\title{
ARTICLE \\ Physiological and lipid profile response to acute exercise at different intensities in individuals with spinal cord injury
}

Eduardo S Alves ${ }^{1,2}$, Ronaldo VT Santos ${ }^{1,2}$, Francieli S Ruiz ${ }^{1}$, Fabio S Lira ${ }^{3}$, Alexandre A Almeida ${ }^{4}$, Giscard Lima ${ }^{2}$, Thatiana CS Goni ${ }^{2}$, Lila Oyama ${ }^{5}$, Kate M Edwards ${ }^{6}$, Sergio Tufik ${ }^{1}$ and Marco Túlio De Mello ${ }^{1,2,7}$

STUDY DESIGN: Experimental and cross-sectional study.

OBJECTIVE: To assess the immediate effect of exercise on heart rate (HR), oxygen uptake $\left(\mathrm{VO}_{2}\right)$, pulmonary ventilation (PV), oxygen pulse (OP), glucose and lipids of wheelchair basketball players with spinal cord injury (SCl).

SETTING: Center of Studies in Psychobiology and Exercise-São Paulo, Brazil.

METHODS: In all, nine wheelchair basketball players with $\mathrm{SCl}$ and nine able-bodied controls (C) performed three exercise sessions at different intensities: ventilatory threshold 1 (VT1), 15\% below VT1 and 15\% above VT1 with a duration of $\sim 24-34$ min. HR, VO PV, OP, glucose and lipids were analyzed.

RESULTS: $\mathrm{VO}_{2}, \mathrm{PV}$ and OP were significantly lower in the players with $\mathrm{SCl}$ compared to $\mathrm{C}$ during the same intensity exercise sessions. However, the individuals with $\mathrm{SCls}$ demonstrated increases in $\mathrm{HR}, \mathrm{PV}$ and $\mathrm{OP}$ at similar rates to $\mathrm{C}$. Triglycerides of the $\mathrm{SCl}$ group were elevated $30 \mathrm{~min}$ after the exercise session at VT1 compared to values before the exercise session $(P=0.017)$; this elevation was not observed in group C. For the exercise sessions $15 \%$ above VT1, only glucose $(P=0.040)$ and low-density lipoprotein $(P=0.012) 30$ min after the exercise were elevated in the $\mathrm{SCl}$ group compared to group $\mathrm{C}$. CONCLUSION: We conclude that the $\mathrm{SCl}$ group demonstrated increases in $\mathrm{HR}, \mathrm{PV}$ and $\mathrm{OP}$ but not $\mathrm{VO}_{2}$ with increased intensity of exercise at similar rates as in group $C$.

Spinal Cord Series and Cases (2017) 3, 17037; doi:10.1038/scsandc.2017.37; published online 6 July 2017

\section{INTRODUCTION}

Individuals with complete spinal cord injury ( $\mathrm{SCl}$ ) show sensory and motor deficits that limit energy expenditure in activities performed during the day. ${ }^{1} \mathrm{SCl}$ is also associated with increase in insulin resistance, total cholesterol (TC) and triglycerides (TG) and decrease in high-density lipoprotein (HDL) cholesterol, $^{2-4}$ which can increase cardiovascular diseases and decrease life expectancy after $\mathrm{SCl}^{5}$

Hicks et al., ${ }^{6}$ showed evidence that acute and chronic exercise (physical training) can improve the physical conditioning and lipid profile of individuals with $\mathrm{SCl}$, thereby decreasing the incidence of cardiovascular disease. These cardiometabolic benefits depend on the intensity and volume of exercise. ${ }^{6}$ Aerobic arm ergometry training, performed 2-3 times per week at a moderate intensity ( $60-80 \%$ of max heart rate $(\mathrm{HR})$, or $60-65 \%$ peak oxygen consumption $\left(\mathrm{VO}_{2}\right.$ peak)) with a duration of more than $30 \mathrm{~min}$, improves physical capacity as measured by $\mathrm{VO}_{2}$ peak in $\mathrm{SCl}^{6}$

During aerobic exercise $(\mathrm{AE})$, increments in oxygen uptake $\left(\mathrm{VO}_{2}\right)$ and $\mathrm{HR}$ are expected to occur proportionally to increases in exercise intensity. ${ }^{7}$ These variables remain constant during a $30 \mathrm{~min}$ session of $\mathrm{AE}$ but increase with increased exercise intensity. ${ }^{7,8}$ However, lower absolute values are obtained when exercise is performed using the upper limbs compared to the lower limbs. ${ }^{9}$ Little is known about the response of physiological variables in individuals with $\mathrm{SCl}$ during acute exercise sessions at different intensities when compared to a control group without $\mathrm{SCl}$.

Transient changes in lipid and carbohydrate metabolism are responsible for maintaining energy supply to active muscles during acute physical exercise, ${ }^{10}$ and in non-SCl populations they are directly related to the intensity and/or volume of physical exercise. ${ }^{10,11}$ However, only one study has compared the effect of acute exercise on the lipid profile of individuals with $\mathrm{SCl}$ with non- $\mathrm{SCl}$ able-bodied $(\mathrm{AB})^{12}$ individuals. Lipid profiles of $\mathrm{SCl}$ and $\mathrm{AB}$ individuals were compared during a single 30 -min exercise session at $60 \% \mathrm{VO}_{2}$ peak of aerobic at baseline, before and after 16 weeks of aerobic training. ${ }^{12}$ Immediately after the pretraining exercise session, the authors observed an increase in HDL cholesterol in volunteers without $\mathrm{SCl}$, suggesting a different metabolic response during an exercise session of similar relative intensity.

The present study was designed to determine the effect of different intensities of acute exercise on $\mathrm{HR}, \mathrm{VO}_{2}$, pulmonary ventilation (PV), OP, glucose and lipids in wheelchair basketball players with $\mathrm{SCl}$ as compared to $\mathrm{AB}$ controls. We hypothesized that an increase in the relative intensity of acute exercise leads to a higher absolute physiological response in $\mathrm{AB}$ controls compared to wheelchair basketball players with $\mathrm{SCl}$, but with proportional increments between groups when intensity is increased. In addition, we hypothesized that this condition would induce a higher impact in the glucose and lipid profiles in $A B$ controls compared to wheelchair basketball players with $\mathrm{SCl}$.

\footnotetext{
${ }^{1}$ Departamento de Psicobiologia, Universidade Federal de São Paulo-UNIFESP, Sao Paulo, Brazil; ${ }^{2}$ Centro de Estudos em Psicobiologia e Exercício-CEPE, São Paulo, Brazil; ${ }^{3}$ Exercise and Immunometabolism Research Group, Department of Physical Education, University State Estadual Paulista, UNESP, Presidente Prudente, Sao Paulo, Brazil; ${ }^{4}$ Departamento de Fisiologia, Universidade Federal de São Paulo-UNIFESP, Sao Paulo, Brazil; ${ }^{5}$ Post-graduate Program in Nutritional Sciences, Universidade Federal de São Paulo-UNIFESP, Sao Paulo,

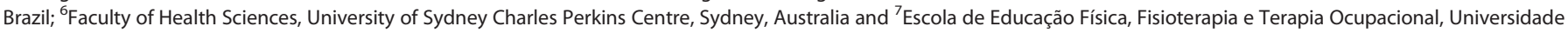
Federal de Minas Gerais-UFMG, Minas Gerais, Brazil.
}

Correspondence: MT De Mello (tmello@demello.net.br)

Received 22 December 2015; revised 15 May 2017; accepted 17 May 2017 


\section{METHODS}

All procedures in the study were approved by the Universidade Federal de Sao Paulo Research Ethics Committee (0294/11) and are in agreement with Brazilian norms for research involving humans (Resolution 196; October 10, 1996). All volunteers provided written consent to participate in the study.

\section{Sample population}

Eighteen male volunteers (nine wheelchair basketball players with $\mathrm{SCl}$ and nine physically active $A B$ controls (C)) participated in the study. Subjects with $\mathrm{SCl}$ (were at least 1 year post injury) had lesions between T7 and L1 $(\mathrm{ASI} A-\mathrm{A})^{13}$ and had played basketball regularly for 4 years. Inclusion criteria were age above 18 years and older, wheelchair as the only mode of locomotion and normal stress electrocardiogram. Exclusion criteria included the presence of cardiovascular disease, diabetes, chronic or acute inflammatory disease and use of medication for dyslipidemia.

Body mass was measured using an electronic scale modified for use with wheelchairs (Tanita 4521, Tanita Corporation of America. Arlington Heights, IL USA.). Height was measured with the volunteer lying down over a flat surface, and measurements were recorded at the distal points between the head and feet at a $90^{\circ}$ position. Body composition was analyzed using air-displacement plethysmography (Bod POD, Cosmed. Concord, CA, USA).

\section{Experimental design}

Subjects were assessed in the laboratory during five different sessions. In session one, subjects received information regarding the study and underwent resting and stress electrocardiograms.

During session two, subjects underwent an ergospirometry test to determine peak oxygen consumption (peak $\mathrm{VO}_{2}$ ) and ventilatory threshold 1 (VT1). Subjects then returned for three exercise sessions of different intensities (third, fourth and fifth sessions) (adapted from Tsal et al.). ${ }^{14}$ These were conducted between $48 \mathrm{~h}$ and 7 days after previous session to ensure complete recovery. The intensities of the three exercise sessions were designed to achieve peak $\mathrm{VO}_{2}$ at $\mathrm{VT} 1,15 \%$ below $\mathrm{VT} 1$ and $15 \%$ above VT1. The exercise volume of the first acute exercise session (third visit) was controlled, so that all volunteers in both groups exercised for $30 \mathrm{~min}$.

The calorie expenditure (CE) of each subject $\left(\mathrm{kcal} \mathrm{min}^{-1}\right)$ was estimated during the exercise sessions. During the sessions at $15 \%$ below VT1 and $15 \%$ above VT1, the exercise time was calculated based on the subject's CE at VT1 for $30 \mathrm{~min}$. The exercise protocol used exercises of different intensities and similar energetic expenditure (isoenergetic) for a similar group during different sessions. Exercise volumes for group $\mathrm{C}$ during acute exercise sessions at $15 \%$ below VT1, VT1 and $15 \%$ above VT1 were $34.2 \mathrm{~min}$ (s.d.=0.9), $30 \mathrm{~min}$ and $24.6 \mathrm{~min}$ (s.d. $=0.9$ ), respectively. In the $\mathrm{SCl}$ group, exercise volumes during acute exercise sessions at $15 \%$ below VT1, VT1 and 15\% above VT1 were $34.7 \pm 1.2,30$ and $24.2 \pm 0.9 \mathrm{~min}$, respectively.
Establishing peak $\mathrm{VO}_{2}$ and ventilatory threshold (VT1)

To establish peak $\mathrm{VO}_{2}$ and $\mathrm{VT} 1$, in the second session, subjects performed an incremental test until exhaustion. Control subjects were tested using a traditional treadmill (Lifefitness $9100 \mathrm{HR}$, Schiller Park, IL, USA), and SCI subjects were tested using a treadmill that was modified for wheelchair use.

Control subjects began the test at a treadmill incline of $1 \%$ and a speed of $5 \mathrm{~km} \mathrm{~h}^{-1}$ for $3 \mathrm{~min}$; after this phase, the speed was increased by $1 \mathrm{~km} \mathrm{~h}^{-1} \mathrm{~min}^{-1}$ until maximum voluntary exhaustion. The subjects with $\mathrm{SCl}$ began the test at a fixed $1 \%$ incline and a speed of $6 \mathrm{~km} \mathrm{~h}^{-1}$ for $3 \mathrm{~min}$, and the speed was increased by $1 \mathrm{~km} \mathrm{~h}^{-1}$ per minute until maximum voluntary exhaustion. Maximum voluntary exhaustion was determined based on the volunteer's report of muscle fatigue, general fatigue, muscle or joint soreness, $\mathrm{VO}_{2}$ plateau $\left(\leqslant 150 \mathrm{ml} \mathrm{min}^{-1}\right)$, attainment of the percentage of the age-predicted maximal $H R\left(H_{\text {peak }}\right)$ within \pm 5 beats $\mathrm{min}^{-1}$, respiratory exchange ratio $\geqslant 1.10$ or the loss of the coordination required to maintain the treadmill pace (running strides or wheelchair spinning). ${ }^{15} \mathrm{~A}$ gas analyzer was used to determine respiratory variables, including peak $\mathrm{VO}_{2}$ and $\mathrm{VT} 1$, as well as VT1 loads. Peak $\mathrm{VO}_{2}$ was estimated based on the highest relative $\mathrm{VO}_{2}\left(\mathrm{ml} \mathrm{kg}^{-1} \mathrm{~min}^{-1}\right)$ obtained at the end of the test. To determine VT1, two independent evaluators observed the criteria adopted by Gaskill et al. ${ }^{16}$ These variables were obtained by analyzing pulmonary gas exchange using a gas analyzer (Quark PFT 4Ergo, Cosmed, Rome, Italy). The gas analyzer was calibrated immediately before each protocol using a preset concentration of gases. Ventilatory volume and flow were calibrated using a 3-L air syringe. A Hans Rudolph flow-by face mask (Kansas City, MO, USA) was used.

$\mathrm{HR}$ was registered every $5 \mathrm{~s}$ using a short-distance telemetry system (RS800CX, Polar Electro Oy, Kempele, Finland). Respiratory variables were measured using a gas analyzer that recorded ventilatory variables after each respiratory cycle; the analyzer was calibrated before each test according to the manufacturer's instructions. $\mathrm{O}_{2}$ and $\mathrm{CO}_{2}$ analyzers were calibrated using preset gas concentrations, and the volume sensor was calibrated using a 3-L syringe.

Acquisition of physiological variables during acute exercise For the evaluation of $\mathrm{HR}, \mathrm{OP}, \mathrm{VO}_{2}$ and $\mathrm{PV}$, measurements were obtained and analyzed during the last $5 \mathrm{~min}$ of exercise; average values were calculated using Excel software (Microsoft Office Excel, 2007, Microsoft. Mountain View, CA USA). HR was obtained by telemetry, and $\mathrm{VO}_{2}$ and PV were obtained using a gas analyzer. OP $\left(\mathrm{ml} \mathrm{beat}^{-1}\right)$ was calculated by dividing the absolute $\mathrm{VO}_{2}$ by $\mathrm{HR}$ in beats per minute.

\section{Blood collection and analysis}

Blood samples were collected before, immediately after and $30 \mathrm{~min}$ after the acute exercise sessions. Glucose, triglycerides (TG), total cholesterol (TC) and HDL were assessed using commercial enzymatic assay kits (Labtest, Sao Paulo, Brazil). Low-density lipoprotein (LDL), cholesterol and very-low-density lipoprotein were calculated according to Friedewald et al. ${ }^{17}$

Table 1. Chronological age, anthropometric and cardiorespiratory characteristics of subjects

\begin{tabular}{|c|c|c|c|}
\hline Age (years) & $27.0(24.00-31.00)$ & $29.00(26.50-36.00)$ & 0.269 \\
\hline Height $(\mathrm{cm})$ & 179.50 (172.33-183.50) & 168.00 (164.50-175.50) & 0.086 \\
\hline $\mathrm{BF}(\%)$ & $13.00(11.88-15.50)$ & $15.65(11.68-21.75)$ & 0.265 \\
\hline $\mathrm{VO}_{2 \text { base }}\left(\mathrm{ml} \mathrm{kg}^{-1} \mathrm{~min}^{-1}\right)$ & $3.5(2.8-4.2)$ & $3.3(3.3-3.6)$ & 0.659 \\
\hline $\mathrm{HR}_{\text {base }}$ (b.p.m.) & $69(64-70)$ & $72(66-76)$ & 0.132 \\
\hline $\mathrm{PV}_{\text {base }}\left(I \min ^{-1}\right)$ & $7.2(6.5-8)$ & $6.5(5.9-7)$ & 0.287 \\
\hline $\mathrm{HR}_{\text {peak }}$ (b.p.m.) & $191.00(182.75-197.75)$ & $192.00(170.00-200.00)$ & 0.772 \\
\hline $\mathrm{PV}_{\text {peak }}\left(I \mathrm{~min}^{-1}\right)$ & $139.40(130.85-158.40)$ & $99.20(82.20-107.90)^{*}$ & 0.003 \\
\hline $\mathrm{OP}_{\text {peak }}\left(\mathrm{ml}\right.$ beat $\left.^{-1}\right)$ & $16.55(13.58-19.00)$ & $11.90(10.50-12.47)^{*}$ & 0.002 \\
\hline
\end{tabular}

Abbreviations: base, baseline; b.p.m., beats per minute; $\mathrm{BP}$, body fat; $\mathrm{cm}$, centimeters; HR, heart rate; $\mathrm{kg}$, kilograms; I min $^{-1}$, liters per minute; $\mathrm{ml}$ beat ${ }^{-1}$, milliliter per beat; $\mathrm{ml} \mathrm{kg}^{-1} \mathrm{~min}^{-1}$, milliliter kilograms minute; min, minute; $\mathrm{OP}$, oxygen pulse; $\mathrm{PV}$, pulmonary ventilation; $\mathrm{SCl}$, spinal cord injury; $\mathrm{VO}_{2}$, oxygen uptake; \%, percentage.

$P$-value for Mann-Whitney test. Values are expressed as median and quartile 1 and 3. 


\section{Statistical analysis}

Results were compared using nonparametric analysis. Comparisons between groups were performed using the Mann-Whitney test. To compare differences based on the data collection time within the same group, Friedman's analysis of variance was used. When significant differences were found using Friedman's test, the Wilcoxon test was repeatedly performed to identify the time points for which the differences were observed. In the latter test, the $P$-value was corrected based on the number of comparisons performed (Bonferroni correction). The average of percentage variations (((final value - initial value)/initial value) $\times 100)$ of $H R_{\text {, }}$ $\mathrm{VP}, \mathrm{OP}$ and $\mathrm{VO}_{2}$ was calculated for each intensity of acute exercise. Analyses were performed using SPSS version 20.0 (SPSS Inc., Armonk, NY, USA). Values are presented as medians and interquartile ranges. The significance level adopted was $P<0.05$.

\section{RESULTS}

Anthropometric and cardiorespiratory characteristics

Table 1 shows anthropometric and cardiorespiratory characteristics of participants. Results were as expected because of the $\mathrm{SCl}$ group using a lower amount of involved muscle mass during physical exercise compared to group C.

Cardiorespiratory responses in groups $\mathrm{C}$ and $\mathrm{SCl}$ during the last 5 min of exercise with different intensities

Figure 1 shows $\mathrm{HR}, \mathrm{PV}, \mathrm{VO}_{2}$ and $\mathrm{OP}$ response to physical exercise at different intensities in both groups $\mathrm{C}$ and $\mathrm{SCl}$ during the last $5 \mathrm{~min}$ of each exercise session. Work performed during the physical exercise was measured based on the total CE of each volunteer during the three different intensities of $A E$. CE during the exercise sessions did not significantly differ (isoenergetic) at $15 \%$ below VT1, VT1 and at 15\% above VT1 exercise intensities in group C (340 (300-395 kcal), $342 \quad(301-392 \mathrm{kcal})$ and 340 (304-391.5 kcal), respectively) (Group $\left.C X_{(2)}^{2}=2.800, P=0.24\right)$ or in the SCl group (168 (127.5-220 kcal), $172(127-218 \mathrm{kcal})$ and 165 (125-216 kcal), respectively) (Group SCI X $\left.{ }^{2}(2)=3.250, P=0.197\right)$.

Cardiorespiratory response during the last $5 \mathrm{~min}$ of exercise at $15 \%$ below VT1

$\mathrm{PV}, \mathrm{VO}_{2}$ and $\mathrm{OP}$ were significantly lower during the last $5 \mathrm{~min}$ of the exercise session at $15 \%$ below VT1 in the SCl group compared to group $C(P \leqslant 0.001)$. CE was also significantly lower in the $\mathrm{SCl}$ group (168 (127.5-220 kcal)) than in group C (340 (300-395 kcal)) $(P \leqslant 0.001)$. These results were expected because the $\mathrm{SCl}$ group used a lower active muscle mass during physical exercise compared to group C. HR did not significantly differ between groups at this exercise intensity $(P=0.102)$ (Figures $1 \mathrm{a}-\mathrm{d}$ ).

Cardiorespiratory responses during the last $5 \mathrm{~min}$ of exercise at VT1

$\mathrm{PV}, \mathrm{VO}_{2}$ and OP during the last $5 \mathrm{~min}$ of the exercise session at VT1 were significantly lower in the $\mathrm{SCl}$ group compared to control subjects $(P<0.001)$. CE was also significantly lower in the $\mathrm{SCl}$ group (172 (127-218 kcal)) than in controls (342 (301-392 kcal)) $(P \leqslant 0.001)$. These results were expected because $\mathrm{SCl}$ group used less muscle mass during the physical exercise compared to group C. HR did not significantly differ between groups at this exercise intensity $(P=0.199)$ (Figures 1a-d).
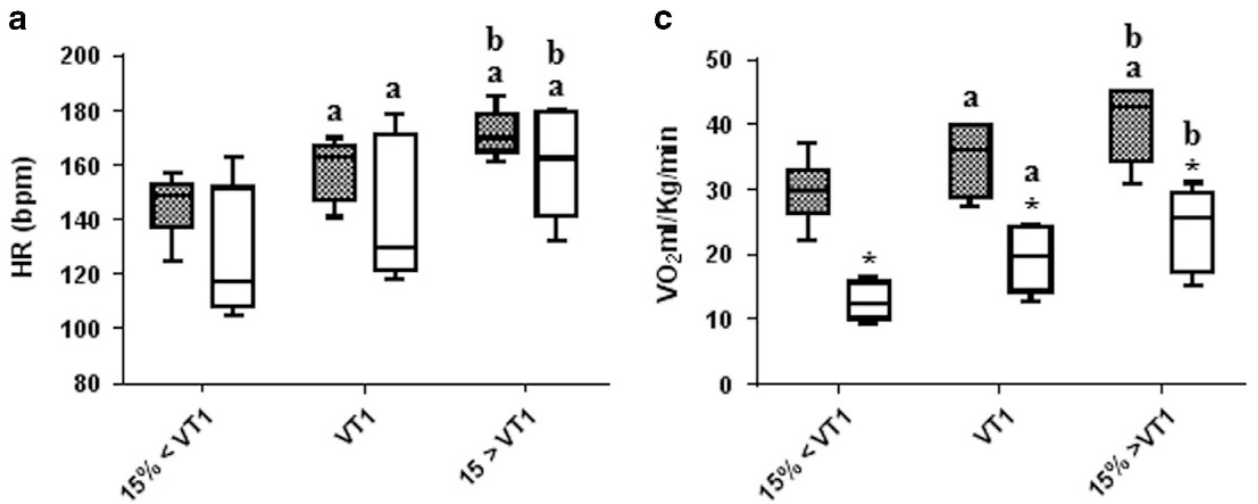

W6 CONTROL
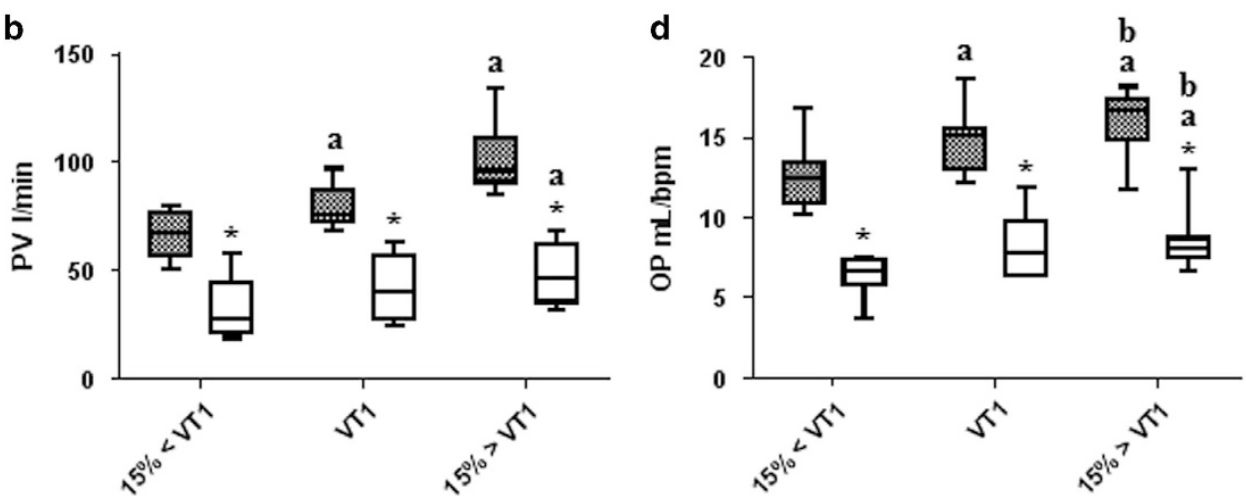

Figure 1. Box plots showing $\mathrm{HR}(\mathbf{a})$, oxygen uptake $\left(\mathrm{VO}_{2}\right)(\mathbf{b}), \mathrm{PV}(\mathbf{c})$ and $\mathrm{OP}(\mathbf{d})$ during the last 5 min of aerobic exercise at $15 \%$ below VT1 (15\% $<\mathrm{VT} 1)$, VT1 and $15 \%$ above VT1 (15\% > VT1). HR, heart rate; PV, pulmonary ventilation; $\mathrm{VO}_{2}$, peak oxygen uptake; b.p.m., beats per minute; ml per bmp, milliliters per beat; I $\mathrm{min}^{-1}$, liters per minute; $\mathrm{ml} \mathrm{kg}^{-1} \mathrm{~min}^{-1}$, milliliters per kilogram of body mass per minute; VT1, ventilatory threshold $1 ;{ }^{*}$ significant difference in the control group at a similar exercise intensity; ${ }^{a}$ significant difference in exercise at $15 \%$ below VT1 $(P<0.05)$; and ${ }^{b}$ significant difference in exercise at VT1 $(P<0.05)$. Values are expressed as medians, minimum, maximum and first and third quartiles (25th and 75 th percentiles). 


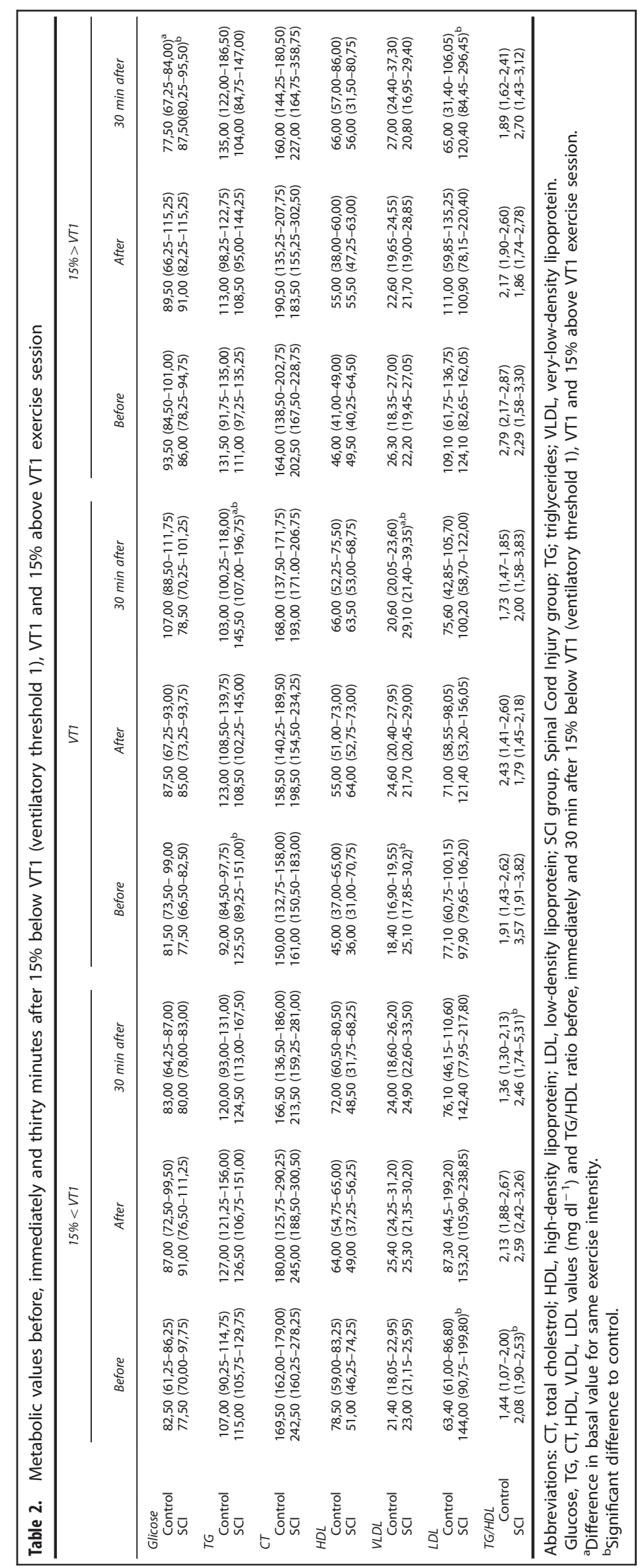


Cardiorespiratory response during the last $5 \mathrm{~min}$ of exercise at $15 \%$ above VT1

$\mathrm{PV}, \mathrm{VO}_{2}$ and OP during the last $5 \mathrm{~min}$ of the exercise session at $15 \%$ above VT1 were significantly lower in the $\mathrm{SCl}$ group than in group $C(P \leqslant 0.001)$. CE was also significantly lower in the $\mathrm{SCl}$ group (165 (125-216 kcal)) than in group C (340 (304-391.5 kcal)) $(P \leqslant 0.001)$. These results were expected because the subjects with $\mathrm{SCl}$ used less muscle mass during the physical exercise compared to group C. HR did not significantly differ between groups at this exercise intensity $(P=0.268)$ (Figures $1 \mathrm{a}-\mathrm{d})$.

Average of percentage variations of $\mathrm{HR}, \mathrm{VP}, \mathrm{OP}$ and $\mathrm{VO}_{2}$ between exercise sessions

We compared the relative values of $\mathrm{HR}, \mathrm{VP}, \mathrm{OP}$ and $\mathrm{VO}_{2}$ between groups, minimizing the fact that the groups did physical exercise with different muscle masses. In group $C, H R(P=0.01)$, VP $(P=0.01)$, OP $(P=0.01)$ and $\mathrm{VO}_{2}(P=0.01)$ were higher in the exercise session at $15 \%$ below VT1 compared to baseline. In the $\mathrm{SCl}$ group, $\mathrm{HR}(P=0.01), \mathrm{VP}(P=0.01), \mathrm{OP}(P=0.03)$ and $\mathrm{VO}_{2}$ $(P=0.02)$ were higher in the exercise session at $15 \%$ below VT1 compared to baseline condition.

There were no differences in percent variations between exercise sessions at $15 \%$ below VT1 and VT1 in HR ((9.2 (5.5-11.1\%) vs 13.1 (7.2-14.7\%) $(P>0.05))$, PV ((21.6(0-24.8\%) vs $18.5(6.1-28.9 \%) \quad(P>0.05))$, OP $((18.7 \quad(-8.8-23.5 \%) \quad$ vs 17.6(-1.3-61.9\%) $(P>0.05))$. However, there were higher percentage variations of $\mathrm{VO}_{2}$ in the $\mathrm{SCl}$ group compared to group $\mathrm{C}((16.8$ $(7.5-23.5 \%)$ vs $44.6 \quad(18-56.4 \%) \quad(P=0.01))$. There were no differences between groups in exercise sessions at VT1 and at $15 \%$ under VT1 in HR (7.1 (1.7-10.4\%) vs $7.3(4.3-7.8 \%)(P>0.05))$, PV $((22.8(10.3-37.5 \%)$ vs $19(-2.6-30 \%) \quad(P>0.05))$ and OP $((11.9(-8 .-15.2 \%)$ vs $8.6(-19.4-12.1 \%)(P>0.05))$. However, there were higher average values of percentage variations of $\mathrm{VO}_{2}$ in the $\mathrm{SCl}$ group compared to group C ((14 (8-19.9\%) vs 24.7 (16-29.2\%) $(P=0.02))$ Figure 1.

Blood glucose and lipid profile responses to exercise at 15\% below VT1

$\mathrm{LDL}(P=0.028)$ and the TG/HDL ratio $(P=0.021)$ were higher in the $\mathrm{SCl}$ group compared to group $C$ at rest. Furthermore, 30 min after the $15 \%$ below VT1 exercise session, the TG/HDL ratio remained higher in the $\mathrm{SCl}$ group compared to group $\mathrm{C}(P=0.036)$ (Table 2$)$.

Blood glucose and lipid profile responses to exercise session at VT1

Before the exercise session at an intensity corresponding to VT1, TG and very-low-density lipoprotein ( $P=0.046$ for both) were elevated in the $\mathrm{SCl}$ group compared to control subjects. Values remained elevated $30 \mathrm{~min}$ after the exercise session at the same intensity ( $P=0.027$ for both) (Table 2$)$.

In group $C\left(X_{(2)}^{2}=9.000 ; P=0.011\right)$ and in the $S C l$ group $\left(X_{(2)}^{2}=7.467\right.$; $P=0.024)$, TG differed among collection time points. Thirty minutes after the VT1 exercise session, the TG of the $\mathrm{SCl}$ group were higher relative to the values measured at rest $(T=-2.395 ; P=0.017)$; this result was not observed in group $C(P>0.017)$ (Table 2$)$.

Blood glucose and lipid profile responses to exercise sessions at $15 \%$ above VT1

Glucose $(P=0.040)$ and LDL $(P=0.012)$ were the only values that were elevated 30 min after the exercise session at $15 \%$ above VT1 in the $\mathrm{SCl}$ group compared to the control. In control subjects, glucose levels differed among collection time points $\left(X_{(2)}^{2}=6.750\right.$; $P=0.034)$. Thirty minutes after the end of the $15 \%$ above VT1 exercise session, the glucose level was lower than that at rest $(T=-2.521 ; P=0.012$ ) (Table 2).

\section{DISCUSSION}

In this study, wheelchair basketball players with $\mathrm{SCl}$ exhibited lower absolute physiological responses than $A B$ controls during acute exercise at similar relative intensity, except for FC. Except for $\mathrm{VO}_{2}$, both groups had comparable increases in physiological responses during acute exercise of similar relative intensity. Changes both at rest and at different intensities of acute physical exercise were found with baseline and transient glucose and lipid profiles. These changes did not follow a pattern between groups, probably due to the lower energy expenditure in the $\mathrm{SCl}$ group compared to controls at the same relative intensity, and the difference between the type of exercise performed (running vs wheelchair).

$\mathrm{HR}$ is used as an indicator of exercise intensity and is correlated with workload during acute exercise in individuals with $\mathrm{SCl}$. Therefore, a higher exercise intensity or workload results in a higher HR. ${ }^{8,18}$ Despite a lower muscle mass during physical exercise, no difference in HR was found between a subject with $\mathrm{SCl}$ with paraplegia and control subjects at any exercise intensity. ${ }^{18}$ On the basis of the HR responses during exercises of three intensities in the $\mathrm{SCl}$ group (as in response in the $\mathrm{C}$ group), $\mathrm{HR}$ can be used to prescribe and monitor training intensity in wheelchair basketball players with spinal cord disruption below T7.

Oxygen pulse (OP) is defined as a product of $\mathrm{HR}$ and $\mathrm{VO}_{2}$, and it may also be an indirect measure of systolic volume and arteriovenous oxygen difference. It is an important variable due to its association with several cardiac dysfunctions. ${ }^{19}$ The reason the $\mathrm{SCl}$ group exhibited lower absolute OP values as compared to control subjects during exercise of similar relative acute intensity is likely the lower systolic volume used during exercise performed with the upper limbs versus the lower limbs. ${ }^{20}$

Oxygen uptake $\left(\mathrm{VO}_{2}\right)$ is calculated by multiplying the cardiac output (HR $\times$ systolic volume) and the arteriovenous oxygen difference in tissue capillaries and is closely related to metabolic demands in muscles during exercise. ${ }^{7}$ In our study, significant increases in $\mathrm{VO}_{2}$ and $\mathrm{HR}$ occurred with incremental increases in acute exercise intensity. Even though $\mathrm{HR}$ influences $\mathrm{VO}_{2}$, we found lower absolute values of $\mathrm{VO}_{2}$ in the $\mathrm{SCl}$ compared to control subjects at all exercise intensity levels. Systolic volume was lower in the upper limbs than during exercise performed with the lower limbs, resulting in lower $\mathrm{VO}_{2}$ measurements in the $\mathrm{SCl}$ group. ${ }^{1,13,18}$ In the present study, the percent of variations in $\mathrm{VO}_{2}$ between intensities was higher in the $\mathrm{SCl}$ group compared with controls. Kang et al. ${ }^{21}$ found that lower work and metabolic efficiency in the upper extremities was caused by the use of a greater percentage of energetically inefficient fast-twitch muscle fiber as compared to the lower extremities. We suggest that this lower efficiency is the reason for our $\mathrm{VO}_{2}$ results.

During acute exercise, the PV response is determined by the activity of the central nervous system, which is mediated by muscle contractions and peripheral sensory input from chemoreceptors and mechanoreceptors that are located in the joints, muscles and tendons. ${ }^{22}$ Because active muscle mass is lower in individuals with $\mathrm{SCl}$, peripheral sensory input is decreased, resulting in a lower activation/response of the respiratory system and lower ventilation values compared to control individuals. ${ }^{22}$

Our protocol used exercises of different intensities with similar energetic expenditure (isoenergetic) for similar groups during different sessions; hence, control and $\mathrm{SCl}$ subjects consumed similar calories to perform three sessions of acute exercise at different intensities. We did not find significant variations in lipid profile in control subjects, regardless of exercise intensity. Findings are consistent with previous literature, which indicate that shortterm exercise produces little to no change in the plasma 
concentrations of lipoproteins reference. In addition, this may be due to lack of sufficient exercise intensity in our study.

In controls, blood glucose was lower at $30 \mathrm{~min}$ after exercise performed at $15 \%$ above VT1 than that before exercise. During exercise performed at an elevated intensity, the consumption and uptake of glucose by active muscles increases with exercise intensity due to the higher contribution of anaerobic metabolism, especially at exercise intensities above VT1 $1{ }^{11}$ We did not find any difference in blood glucose during three different intensities of acute exercise in the $\mathrm{SCl}$ group. This point can, at least in part, be related to low energy expenditure.

Despite lower caloric expenditure, triglycerides and very-lowdensity lipoprotein were higher at $30 \mathrm{~min}$ after the exercise session at VT1 in the $\mathrm{SCl}$ group. Despite similar exercise intensity, 30 min of moderate acute physical activity might have different repercussions when involving upper limbs than lower limbs. ${ }^{23-25}$ Furthermore, individuals with $\mathrm{SCl}$ might exhibit higher sensitivity to catecholamines, thereby increasing lipolysis in adipose tissue ${ }^{26}$ and leading to a decrease in the ability to oxidize fat in skeletal muscle at rest, as well as increasing TG and very-low-density lipoprotein 30 min after an exercise session. ${ }^{27,28}$

When comparing values of blood glucose and lipids between groups when exercise at $15 \%$ below VT1 was performed, the SCl group exhibited higher LDL values and TG/HDL ratios before the exercise session than control subjects, suggesting that the $\mathrm{SCl}$ group had elevated lipid profiles and possible increased cardiovascular risk compared to people without $\mathrm{SCl}^{28} \mathrm{~A}$ single exercise session at $15 \%$ below VT1 for approximately 30 min was able to attenuate the difference in LDL between the groups, although a similar response was not observed for the TG/HDL ratio. When acute exercise was performed at VT1, the $\mathrm{SCl}$ group exhibited higher TG levels before the exercise session but not immediately after the session. Blood glucose and LDL were also higher in the $\mathrm{SCl}$ group compared to group C 30 min after the exercise performed at $15 \%$ above VT1.

Limitations of the present study include the fact that control subjects did not perform arm ergometry, which would have allowed us to identify the effect of $\mathrm{SCl}$ or exercise mode in relation to the upper limbs separately, and to better understand the impact of each of these variables on the parameters evaluated in this study. Our results might also not extrapolate higher exercise intensities.

Taken together, our data demonstrated that wheelchair basketball players with $\mathrm{SCl}$ presented relative physiological responses at similar rates compared with the control group $C$ with increased intensity of acute exercise, except in the case of $\mathrm{VO}_{2}$, glucose and TG response. These changes in transient glucose and lipid profiles between groups at the same relative intensity could be explained by the greater increase in $\mathrm{VO}_{2} \%$ in the $\mathrm{SCl}$ group, or because of differences between the muscle mass involved during exercise in the upper versus lower limbs.

\section{ACKNOWLEDGEMENTS}

We thank the Associação Fundo de Incentivo a Pesquisa-AFIP, Conselho Nacional de Desenvolvimento Cientifico e Tecnológico-CNPq), Centro Multidisciplinar em Sonolência e Acidentes-CEMSA, Centros de Pesquisa, Expansão e Difusão do Instituto do Sono-CEPID/SONO, Fundação de Amparo a Pesquisa do Estado de São Paulo-FAPESP and the Centro de Estudos em Psicobiologia e Exercício-CEPE.

\section{COMPETING INTERESTS}

The authors declare no conflict of interest.

\section{REFERENCES}

1 Davis GM. Exercise capacity of individuals with paraplegia. Med Sci Sports Exerc 1993; 25: 423-432.
2 Bauman WA, Spungen AM. Carbohydrate and lipid metabolism in chronic spinal cord injury. J Spinal Cord Med 2001; 24: 266-277.

3 Lavela SL, Weaver FM, Goldstein B, Chen K, Miskevics S, Rajan S et al. Diabetes mellitus in individuals with spinal cord injury or disorder. J Spinal Cord Med 2006; 29: 387-395.

4 Laclaustra M, Van Den Berg EL, Hurtado-Roca Y, Castellote JM. Serum lipid profile in subjects with traumatic spinal cord injury. PLOS ONE 2015; 10: e0115522.

5 Cowan RE, Nash MS. Cardiovascular disease, $\mathrm{SCl}$ and exercise: unique risks and focused countermeasures. Disabil Rehabil 2010; 32: 2228-2236.

6 Hicks AL, Martin Ginis KA, Pelletier CA, Ditor DS, Foulon B, Wolfe DL. The effects of exercise training on physical capacity, strength, body composition and functional performance among adults with spinal cord injury: a systematic review. Spinal Cord 2011; 49: 1103-1127.

7 Ginis KA, Arbour-Nicitopoulos KP, Latimer AE, Buchholz AC, Bray SR, Craven BC et al. Leisure time physical activity in a population-based sample of people with spinal cord injury part II: activity types, intensities, and durations. Arch Phys Med Rehabil 2010; 91: 729-733.

8 Booher MA, Smith BW. Physiological effects of exercise on the cardiopulmonary system. Clin Sports Med 2003; 22: 1-21.

9 Gutin B, Ang KE, Torrey K. Cardiorespiratory and subjective responses to incremental and constant load ergometry with arms and legs. Arch Phys Med Rehabil 1988; 69: 510-513.

10 Thompson PD, Crouse SF, Goodpaster B, Kelley D, Moyna N, Pescatello L. The acute versus the chronic response to exercise. Med Sci Sports Exerc 2001; 33: S438-S445.

11 Richter EA, Hargreaves M. Exercise, GLUT4, and skeletal muscle glucose uptake. Physiol Rev 2013; 93: 993-1017.

12 El-Sayed MS, Younesian A. Lipid profiles are influenced by arm cranking exercise and training in individuals with spinal cord injury. Spinal Cord 2005; 43: 299-305.

13 Jacobs PL, Nash MS. Exercise recommendations for individuals with spinal cord injury. Sports Med 2004; 34: 727-751.

14 Tsao TH, Yang CB, Hsu CH. Effects of different exercise intensities with isoenergetic expenditures on C-reactive protein and blood lipid levels. Res $Q$ Exerc Sport 2012; 83: 293-299.

15 Howley ET, Bassett DR Jr, Welch HG. Criteria for maximal oxygen uptake: review and commentary. Med Sci Sports Exerc 1995; 27: 1292-1301.

16 Gaskill SE, Ruby BC, Walker AJ, Sanchez OA, Serfass RC, Leon AS. Validity and reliability of combining three methods to determine ventilatory threshold. Med Sci Sports Exerc 2001; 33: 1841-1848.

17 Friedewald WT, Levy RI, Fredrickson DS. Estimation of the concentration of low-density lipoprotein cholesterol in plasma, without use of the preparative ultracentrifuge. Clin Chem 1972; 18: 499-502.

18 Schmid A, Huonker M, Barturen JM, Stahl F, Schmidt-Trucksass A, Konig D et al. Catecholamines, heart rate, and oxygen uptake during exercise in persons with spinal cord injury. J Appl Physiol (1985) 1998; 85: 635-641.

19 Oliveira RB, Myers J, Araujo CG, Abella J, Mandic S, Froelicher V. Maximal exercise oxygen pulse as a predictor of mortality among male veterans referred for exercise testing. Eur J Cardiovasc Prev Rehabil 2009; 16: 358-364.

20 Gonzalez-Alonso J. Point: stroke volume does/does not decline during exercise at maximal effort in healthy individuals. J Appl Physiol (1985) 2008; 104: 275-276.

21 Kang J, Robertson RJ, Goss FL, Dasilva SG, Suminski RR, Utter AC et al. Metabolic efficiency during arm and leg exercise at the same relative intensities. Med Sci Sports Exerc 1997; 29: 377-382.

22 Sheel AW, Romer LM. Ventilation and respiratory mechanics. Compr Physiol 2012; 2: 1093-1142.

23 Pendergast DR. Cardiovascular, respiratory, and metabolic responses to upper body exercise. Med Sci Sports Exerc 1989; 21: S121-S125.

24 Schneider DA, Wing AN, Morris NR. Oxygen uptake and heart rate kinetics during heavy exercise: a comparison between arm cranking and leg cycling. Eur J Appl Physiol 2002; 88: 100-106.

25 Calbet JA, Holmberg HC, Rosdahl H, van Hall G, Jensen-Urstad M, Saltin B. Why do arms extract less oxygen than legs during exercise? Am J Physiol Regul Integr Comp Physiol 2005; 289: R1448-R1458.

26 Leicht CA, Goosey-Tolfrey VL, Bishop NC. Spinal cord injury: known and possible influences on the immune response to exercise. Exerc Immunol Rev 2013; 19: 144-163.

27 Kjaer M, Dela F, Sorensen FB, Secher NH, Bangsbo J, Mohr T et al. Fatty acid kinetics and carbohydrate metabolism during electrical exercise in spinal cordinjured humans. Am J Physiol Regul Integr Comp Physiol 2001; 281: R1492-R1498.

28 Jacobs KA, Burns P, Kressler J, Nash MS. Heavy reliance on carbohydrate across a wide range of exercise intensities during voluntary arm ergometry in persons with paraplegia. J Spinal Cord Med 2013; 36: 427-435. 